\title{
Post-traumatic stress disorder in Italy: a comprehensive evaluation of all the ICD comorbidities and gender-related differences
}

\author{
Fabio Ferretti ${ }^{1}$, Andrea Pozza ${ }^{1 *}$ (D) , Letizia Bossini ${ }^{2,3}$, Serena Desantis ${ }^{2,3}$, Miriam Olivola ${ }^{2,3}$, Laura Del Matto ${ }^{2,3}$, \\ Giacomo Gualtieri ${ }^{4}$, Roberto Gusinu ${ }^{4}$, Daiana Bezzini ${ }^{5}$, Andrea Fagiolini ${ }^{2,3}$ and Anna Coluccia ${ }^{1}$
}

\begin{abstract}
Objectives: The association between post-traumatic stress disorder (PTSD) and medical comorbidities is controversial since most studies focused on specific comorbidity and victim types. In Italy, data on this issue are scarce. A comprehensive evaluation of all the ICD medical categories co-occurring in PTSD may orient assessment and treatment during clinical and forensic practice. This is the first study evaluating all the ICD physical comorbidities and gender-related differences in Italian PTSD patients. Eighty-four PTSD patients ( 36 females, 48 males) were included. The Clinician-Administered PTSD Scale, Mini International Neuropsychiatric Interview and Davidson Trauma Scale were administered.
\end{abstract}

Results: Most patients had a PTSD consequent to an accident and half of them presented extreme symptom severity. No gender differences emerged on symptom severity/duration and age at the event. Metabolic (39.29\%), circulatory (20.24\%) and musculoskeletal systems/connective tissue diseases (17.86\%) were the most frequent comorbidities. Metabolic/circulatory diseases were more frequent among males ( $p=0.019$ and $p=0.027$, respectively) while females more frequently showed neoplasms $(p=0.039)$. Physical comorbidities represent a serious complication in PTSD patients and are more prevalent than in the Italian population. While gender is not associated with symptom presentation, it seems to play a key role in specific comorbidities including metabolic, circulatory and neoplastic diseases.

Keywords: Post-traumatic stress disorder, Comorbidity, Medical conditions, Gender differences, Diseases of the circulatory system, Metabolic syndrome, Neoplasms, ICD

\section{Introduction}

Although it has been largely investigated in the literature, the association between post-traumatic stress disorder (PTSD) and medical comorbidities is still controversial, mainly because the majority of the studies focused on specific medical conditions [1-4] or populations such as veterans [5, 6]. According to a review [7], PTSD was associated with greater frequency and severity of cardio-respiratory and gastrointestinal complaints, while a recent study highlighted that chronic or neck problems,

\footnotetext{
*Correspondence: andreapozza7@gmail.com

${ }^{1}$ Department of Medical Sciences, Surgery and Neurosciences, University of Siena, Viale Bracci 16, 53100 Siena, Italy

Full list of author information is available at the end of the article
}

frequent headaches, arthritis or rheumatism and hypertension were highly prevalent in adults with PTSD [8]. A comprehensive investigation of all the physical conditions based on the International Classification of Diseases (ICD) may support assessment and treatment during clinical and forensic medical practice. In Italy, very few studies were dedicated to this topic, most of them related to psychological response to natural $[9,10]$ or humanmade disasters [11] such as terroristic attacks. This is the first study assessing ICD physical comorbidities and the related gender differences in a group of Italian PTSD patients. This work extends the results of studies previously published by the authors $[12,13]$. 


\section{Main text \\ Methods \\ Study design and subjects}

One-hundred eight subjects were assessed for inclusion from 2003 to 2017 at the Department of Psychiatry of Siena $(n=35)$ and at the Italian National Observatory for Victims of Terrorism $(n=73)$. Twenty-four subjects were excluded due to exclusion criteria. Thus, a sample of 84 subjects (average age $=50.36 \pm 12.18$, range $=19-78 ; 36$ females and 48 males) was included. All subjects were diagnosed with PTSD according to DSM-IV criteria [14]. The following exclusion criteria were used: (a) comorbidity with any other psychiatric disorders, (b) intellectual disability, (c) neurological conditions, (d) being on concurrent psychotropic medication or psychotherapeutic treatment, (e) past treatment for PTSD (both medication and psychotherapy). The typologies of events faced by the subjects were classified according to the following categories [15]: war events, physical/sexual violence, accidents, unexpected death of a loved one, network event.

\section{Measures}

Socio-demographic and clinical data were collected by psychiatrists, together with a clinical interview for an overall analysis of the subject's medical conditions. Diseases were classified according to the codes of The International Classification of Diseases, Ninth Revision, Clinical Modification (ICD9CM). The rationale for using ICD9CM categories was that this classification system was the most widely used one in clinical practice in Italy when the study started. The Clinician-Administered PTSD Scale [CAPS; [16] was administered by trained psychiatrists to confirm the diagnosis of PTSD, under the supervision of senior psychiatrists with 5-year experience in interviewing patients. Patients' assessment was completed through the administration of other measures, whose results are not shown in this paper: the Mini International Neuropsychiatric Interview [MINI; [17] was used to assess comorbidity with other psychiatric disorders and the Davidson Trauma Scale [DTS; [18] was chosen to assess frequency and severity of post-traumatic symptoms.

\section{Statistical analysis}

Descriptive statistics were used to analyse patients' characteristics based on gender. Fisher's exact test explored the association of dichotomous categorical variables (positive/negative with regard to comorbidities) with gender, while Student's $t$-test (two-tailed) and MannWhitney's $U$-test (two-tailed) were chosen, according to the violation of normality assumption, to compare means of quantitative measures (CAPS total and subscale scores, PTSD duration and age at the event). For each ICD9CM category, the percentage of positive patients, and its $95 \%$ confidence interval, was computed, with a focus on the Metabolic syndrome, belonging to the Endocrine, nutritional and metabolic diseases. Although these percentages should not be considered a punctual estimation of prevalence since the study design was not crosssectional, and neither a period estimation of prevalence, because of the wide period of patients' recruitment, they have been considered as an approximation of the prevalence estimation. The significance level was set at $p<0.05$ and the IBM-SPSS v23 was used for data analysis.

\section{Results}

For the majority of the patients (Table 1), PTSD was diagnosed as a consequence of an accident $(75.00 \%$ for females and $89.57 \%$ for males), a category including natural disasters and terrorist attacks. Severity of PTSD symptoms was similar across gender and half of the patients showed an extreme level of symptom severity $(50.00 \%$ for females and $45.84 \%$ for males). The CAPS total score was slightly lower in males $(76.69 \pm 23.11)$ than in females $(80.44 \pm 30.42)$, although this difference was not significant. No significant gender differences were also found on PTSD symptoms, age at the event and duration of the disorder, even though males showed a longer duration (167.00 \pm 171.19 months) than females $(140.67 \pm 146.21)$.

Diseases of endocrine, nutritional and metabolic systems showed a high frequency: $57.14 \%$ (CI 46.56-67.72) of the patients suffered from health problems related to this ICD9CM category, and $17.86 \%$ (CI 9.67-26.05) presented a Metabolic syndrome (Table 2).

Diseases of the digestive system (39.29\%; CI 22.2942.29), diseases of the circulatory system $(20.24 \%$; CI 11.65-28.83) and diseases of the musculoskeletal system and connective tissue (17.86\%; CI 9.67-26.05) showed a high frequency as well. The ICD9CM categories with the lowest frequency rate were eye diseases and adnexa $(2.38 \%)$ and certain infectious and parasitic diseases (3.57\%), without considering those health problems due to external causes (e.g., injury, poisoning). Only three out of the fourteen diseases categories were significantly associated with gender. Diseases of the circulatory system were significantly more frequent in males $(29.16 \%)$ than females $(8.33 \%)(p=0.027)$. Another significant association emerged for neoplasms but for this ICD9CM category, females showed a higher proportion $(16.67 \%)$ than males $(2.08 \%)(p=0.039)$. Although the relationship between gender and the ICD code "Endocrine, nutritional and metabolic diseases" was not significant, the subcategory related to metabolic syndrome showed a significantly higher proportion of positive males $(27.08 \%)$ than females $(5.56 \%)(p=0.019)$. None of the 
Table 1 gender comparison of patients' characteristics: event type, PTSD severity categories, CAPS total score, CAPS subscale score, PTSD duration and age at the event

\begin{tabular}{|c|c|c|c|c|}
\hline & Females $(n=36)$ & Males $(n=48)$ & Statistic & $p$ \\
\hline \multicolumn{5}{|l|}{ Event type $^{\mathrm{a}}: n(\%)$} \\
\hline War events & $0(0.00)$ & $2(4.17)$ & & \\
\hline Physical violence & $0(0.00)$ & $1(2.08)$ & & \\
\hline Sexual violence & $1(2.77)$ & $1(2.08)$ & & \\
\hline Accidents & $27(75,00)$ & $43(89,57)$ & & \\
\hline Unexpected death of loved one & $6(16,67)$ & $1(2.08)$ & & \\
\hline Network events & $2(5,56)$ & $0(0.00)$ & & \\
\hline \multicolumn{5}{|l|}{ CAPS categories ${ }^{\mathrm{a}}: \mathrm{n}(\%)$} \\
\hline Slight or sub-threshold & $4(11.11)$ & $4(8.33)$ & & \\
\hline Moderate & $6(16.67)$ & $4(8.33)$ & & \\
\hline Severe & $8(22.22)$ & $18(37.50)$ & & \\
\hline Extreme & $18(50.00)$ & $22(45.84)$ & & \\
\hline CAPS total score (mean \pm SD) & $80.44 \pm 30.42$ & $76.69 \pm 23.11$ & $t_{(63)}=0.560$ & 0.538 \\
\hline \multicolumn{5}{|l|}{ CAPS symptoms (mean \pm SD) } \\
\hline Re-experiencing & $23.89 \pm 9.71$ & $22.83 \pm 7.56$ & $t_{(82)}=0.560$ & 0.560 \\
\hline Avoidance and numbing & $31.30 \pm 14.38$ & $30.00 \pm 10.71$ & $t_{(62)}=0.458$ & 0.649 \\
\hline Hyperarousal & $25.25 \pm 8.64$ & $24.00 \pm 8.04$ & $t_{(82)}=0.683$ & 0.497 \\
\hline Duration of PTSD (months; mean \pm SD) & $140.67 \pm 146.21$ & $167.00 \pm 171.19$ & $M W U=783.000$ & 0.463 \\
\hline Age at the event (mean $\pm S D$ ) & $37.00 \pm 13.64$ & $37.60 \pm 11.69$ & $t_{(82)}=-0.218$ & 0.828 \\
\hline
\end{tabular}

CAPS, Clinician-Administered PTSD Scale; MW U, Mann-Whitney U test; PTSD, Post Traumatic Stress Disorder

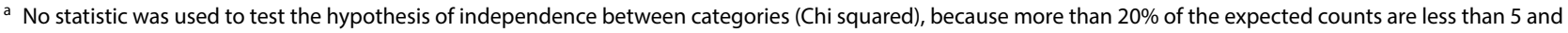
not all individual expected counts are 1 or greater [19]

95\% confidence intervals computed by gender for these categories showed overlapping bounds.

\section{Discussion}

Although in the literature there is a large number of studies concerning the association between PTSD and physical comorbidities, epidemiological data are scarce, particularly in Italy. In addition, previous investigations focused on specific types of comorbidities and there is a lack of a comprehensive assessment of all the ICD categories. The present study is the first one investigating all the ICD medical comorbid conditions and the related gender differences in Italian PTSD patients. Findings showed that specific comorbidities represent a serious issue in PTSD with metabolic, circulatory and musculoskeletal systems/connective tissue diseases being the most frequent ones. While gender is not associated with symptom presentation, it seems to play a key role in specific comorbidities, with males presenting a higher frequency of metabolic/circulatory diseases and females showing more frequently neoplastic conditions.

Comparisons with previous studies related to the prevalence of comorbidities in PTSD patients are difficult due to the different way of coding the pathologies: many studies focused on specific diseases (e.g., diabetes
[20]) instead of all the ICD9CM categories that were used in this paper. Furthermore, existing findings about comorbidities prevalence showed a large degree of heterogeneity, partly due to the differences in study populations (e.g., veterans or general population). As mentioned before, in this study the percentage of positive patients was used as an approximation of the prevalence and this matter makes any comparison more inaccurate. Keeping in mind all these recommendations for the interpretation of the findings, the Italian group of PTSD patients showed interesting similarities and differences with other studies. In this group of subjects, findings showed a percentage of $17.86 \%$ of patients with metabolic syndrome, a proportion that was comparable to the study of Ching-En et al. [21] in Taiwan, where $12.91 \%$ of the PTSD population showed a comorbidity with this disease. Other studies reported much higher values of prevalence: according to the review of Rosenbaum and colleagues [22], the estimation of the metabolic syndrome prevalence in PTSD patients was 38.7\% (CI 32.1-45.6\%) and another study on Bosnian post-war PTSD showed a value of $48.3 \%$ [23].

The development of metabolic syndrome may be due to the stress of the trauma which acts through the neuropeptide Y and glucocorticoid systems [24]. Alternatively, it may be hypothesized that PTSD patients develop 
Table 2 percentage of patients presenting comorbidities and gender comparison related to each disease

\begin{tabular}{|c|c|c|c|c|c|}
\hline & $\%$ (All subjects) $(95 \% \mathrm{Cl})$ & & $\begin{array}{l}\text { Females }(n=36) \\
n(\%)\end{array}$ & $\begin{array}{l}\text { Males }(n=48) \\
n(\%)\end{array}$ & $p^{*}$ \\
\hline \multirow{2}{*}{$\begin{array}{l}\text { Metabolic syndrome (ICD Endocrine, nutritional and metabolic dis- } \\
\text { eases) }\end{array}$} & \multirow[t]{2}{*}{17.86 (9.67 to 26.05) } & Yes & $2(5.56)$ & $13(27.08)$ & \multirow[t]{2}{*}{0.019} \\
\hline & & No & $34(94.44)$ & $35(72.92)$ & \\
\hline \multirow{2}{*}{$\begin{array}{l}\text { ICD Diseases of the blood and blood-forming organs and certain disor- } \\
\text { ders involving the immune mechanism }\end{array}$} & \multirow[t]{2}{*}{10.71 (4.10 to 17.32$)$} & Yes & $5(13.89)$ & $4(8.33)$ & \multirow[t]{2}{*}{0.488} \\
\hline & & No & $31(86.11)$ & $44(91.67)$ & \\
\hline \multirow[t]{2}{*}{ ICD Diseases of the circulatory system } & \multirow[t]{2}{*}{20.24 (11.65 to 28.83$)$} & Yes & $3(8.33)$ & $14(29.16)$ & \multirow[t]{2}{*}{0.027} \\
\hline & & No & $33(91.67)$ & $34(70.83)$ & \\
\hline \multirow[t]{2}{*}{ ICD Diseases of the skin and subcutaneous tissue } & \multirow[t]{2}{*}{$8.33(2.42$ to 14.24$)$} & Yes & $1(2.78)$ & $6(12.50)$ & \multirow[t]{2}{*}{0.230} \\
\hline & & No & $35(97.22)$ & $42(87.50)$ & \\
\hline \multirow[t]{2}{*}{ ICD Diseases of the digestive system } & \multirow[t]{2}{*}{$39.29(22.29$ to 42.29$)$} & Yes & $10(27.78)$ & $23(47.92)$ & \multirow[t]{2}{*}{0.074} \\
\hline & & No & $26(72.22)$ & $25(52.08)$ & \\
\hline \multirow{2}{*}{$\begin{array}{l}\text { ICD Injury, poisoning and certain other consequences of external } \\
\text { causes }\end{array}$} & \multirow{2}{*}{$2.38(-0.88$ to 5.64$)$} & Yes & $0(0.00)$ & $2(4.17)$ & \multirow[t]{2}{*}{0.504} \\
\hline & & No & $36(100.00)$ & $46(95.83)$ & \\
\hline \multirow[t]{2}{*}{ ICD Certain infectious and parasitic diseases } & \multirow[t]{2}{*}{$3.57(-0.40$ to 7.54$)$} & Yes & $0(0.00)$ & $3(6.25)$ & \multirow[t]{2}{*}{0.256} \\
\hline & & No & $36(100.00)$ & $45(93.75)$ & \\
\hline \multirow[t]{2}{*}{ ICD Diseases of the genitourinary system } & \multirow[t]{2}{*}{13.10 (5.88 to 20.32) } & Yes & $5(13.89)$ & $6(12.50)$ & \multirow[t]{2}{*}{1.000} \\
\hline & & No & $31(86.11)$ & $42(87.50)$ & \\
\hline \multirow[t]{2}{*}{ ICD Endocrine, nutritional and metabolic diseases } & \multirow[t]{2}{*}{57.14 (46.56 to 67.72$)$} & Yes & $17(47.22)$ & $31(64.58)$ & \multirow[t]{2}{*}{0.125} \\
\hline & & No & 19 (52.78) & $17(35.42)$ & \\
\hline \multirow[t]{2}{*}{ ICD Neoplasms } & \multirow[t]{2}{*}{8.33 (2.42 to 14.24$)$} & Yes & $6(16.67)$ & $1(2.08)$ & \multirow[t]{2}{*}{0.039} \\
\hline & & No & $30(83.33)$ & $47(97.92)$ & \\
\hline \multirow[t]{2}{*}{ ICD Diseases of the respiratory system } & \multirow[t]{2}{*}{7.14 (1.63 to 12.65$)$} & Yes & $3(8.33)$ & $3(6.25)$ & 1.000 \\
\hline & & No & $33(91.67)$ & $45(93.75)$ & \\
\hline ICD Diseases of the nervous system & 14.29 (6.81 to 21.77$)$ & Yes & $3(8.33)$ & $9(18.75)$ & 0.220 \\
\hline & & No & $33(91.67)$ & $39(81.25)$ & \\
\hline ICD Diseases of the musculoskeletal system and connective tissue & 17.86 (9.67 to 26.05$)$ & Yes & $3(8.30)$ & $12(25.00)$ & 0.082 \\
\hline & & No & $33(91.70)$ & $36(75.00)$ & \\
\hline ICD Diseases of the eye and adnexa & $2.38(-0.88$ to 5.64$)$ & Yes & $1(2.78)$ & $1(2.08)$ & 1.000 \\
\hline & & No & $35(97.22)$ & $47(97.92)$ & \\
\hline
\end{tabular}

* Fisher's exact test (two-tailed)

metabolic problems as a consequence of dysfunctional strategies used to cope with stress such as alcohol drinking [25].

Such a heterogeneity concerns other health-related problems as well. For example, diseases of the circulatory system were reported by $20.24 \%$ of the Italian PTSD patients, by $42 \%$ of a group of refugees psychiatric patients in Asian populations [20], by $5.35 \%$ in Taiwanese general population (both for hypertension) [21], or by 15\% in Australian Vietnam war veterans [26]. An explanation why the stress of the trauma is associated with diseases of the circulatory system may be related to an overactive sympathetic nervous system, haemodynamic reactivity, impaired sympathetic and cardiovagal baroreflex sensitivity, and increased inflammation that could contribute to cardiovascular risk [27].

Lastly, with regard to cancer, it was detected in $8.33 \%$ (a generic neoplasm) of Italian PTSD patients but was reported by $42.2 \%$ (basal cell carcinoma or squamous cell carcinoma) of subjects enrolled in the study of McLeay and colleagues [25]. Again, the comparison between the comorbidities assessed in the Italian PTSD group and the prevalence among the general population, showed the same problem of data comparability, due to the lack of health information coded through the ICD9CM categories. In this study, $17.86 \%$ of the PTSD patients had a metabolic syndrome diagnosis, a percentage which was near to the estimation provided by Miccoli et al. for the Italian population [28]. However, in our study, this disease was more common in women than in men ( $18 \%$ vs. $15 \%)$, the opposite of the findings concerning the Italian group of PTSD patients, where the proportion of subjects with metabolic syndrome was $5.56 \%$ for women and $27.08 \%$ for men. Looking at the ICD9CM code related to neoplasm, this study showed a quite high percentage of subjects affected by this disease $(8.33 \%)$, with a significant gender difference, since $16.67 \%$ of females were diagnosed for neoplasms, compared to $2.08 \%$ of males. 
Data concerning Italian general population did not confirm this difference: according to the AIRTUM Working Group [29], the prevalence in Italy during 2014 was $4.56 \%$, with no substantial difference between females $(4.90 \%)$ and males $(4.20 \%)$. The quite high prevalence of neoplasms in PTSD patients may be attributed to a number of immune changes including increased circulating inflammatory markers, increased reactivity to antigen skin tests, lower natural killer cell activity, and lower total T lymphocyte counts [30].

Much more difficult was the comparison with the Italian general population for the diseases of the circulatory system. Giampaoli et al. [31] estimated that in Italy during the period $2008-2012,1.6 \%$ of men and $0.6 \%$ of women suffered from acute myocardial infarction, 52.5\% of men and $37.8 \%$ of women were diagnosed for hypertension and $0.7 \%$ (both sexes) experienced cerebrovascular accidents. In this study, a percentage of $20.24 \%$ PTSD patients reported a disease of the circulatory system, with a significant gender difference $(29.16 \%$ males vs. $8.33 \%$ females) that is confirmed by the literature and by the general population health status.

In conclusion, this study conducted on a group of Italian PTSD patients confirmed the literature findings on the association between this disorder and medical conditions. Overall, comorbidities showed a high frequency and a higher prevalence than in the Italian general population. Results suggested also that gender may play an important role in developing comorbidities when subjects are affected by PTSD, as suggested by other studies [8]. Our study suggests that assessment and treatment of PTSD patients during clinical and forensic practice should take into account such comorbidities. Due to the limitations of the study design and the difficulty comparing these findings with national and international data, this research brings out the need for deepening this topic in the Italian population.

\section{Limitations}

Although the group of subjects was recruited in a hospital setting and in a national observatory specifically dedicated to PTSD patients, it cannot be considered a true sample of Italian PTSD subjects. The study design did not allow a robust prevalence estimation for each comorbidity since it was not a true cross-sectional study. Another limitation concerns the lack of a comparison group with patients having other psychiatric disorders (e.g., anxiety/ depressive disorders) which can be associated with physical comorbidities [32, 33].

\section{Abbreviations}

CAPS: Clinician-Administered PTSD Scale; DTS: Davidson Trauma Scale; ICD: International Classification of Diseases; ICD9CM: International Classification of Diseases, Ninth Revision, Clinical Modification; MINI: Mini International Neuropsychiatric Interview; PTSD: post-traumatic stress disorder.

\section{Acknowledgements}

Not applicable.

\section{Authors' contributions}

$F F, A P, L B$ and LDM designed the study; LB, SD, MO and LDM contributed to subjects' assessment; FF, AP and DB analyzed data; FF, AP and LDM wrote the manuscript; GG, RG, AF and AC contributed to the results discussion. All authors read and approved the final manuscript.

\section{Funding}

No funding supported this study.

\section{Availability of data and materials}

All data generated or analyzed during this study are included in this published article.

\section{Ethics approval and consent to participate}

The study was approved by the institutional Ethics Committee of the Santa Maria alle Scotte University Hospital of Siena. In accordance with the Helsinki Declaration, patients provided written informed consent to participate to the study.

\section{Consent for publication}

Not applicable.

\section{Competing interests}

The authors declare that they have no competing interests.

\section{Author details \\ ${ }^{1}$ Department of Medical Sciences, Surgery and Neurosciences, University of Siena, Viale Bracci 16, 53100 Siena, Italy. ${ }^{2}$ Department of Molecular Medi- cine, University of Siena School of Medicine, Siena, Italy. ${ }^{3}$ Department of Men- tal Health, University of Siena Medical Center (AOUS), Siena, Italy. ${ }^{4}$ Health Ser- vice Management Board, Santa Maria alle Scotte University Hospital of Siena, Siena, Italy. ${ }^{5}$ Department of Life Sciences, University of Siena, Siena, Italy.}

Received: 3 September 2019 Accepted: 11 November 2019 Published online: 15 November 2019

References

1. Sledjeski EM, Speisman B, Dierker LC. Does number of lifetime traumas explain the relationship between PTSD and chronic medical conditions? Answers from the National Comorbidity Survey-Replication (NCS-R). J Behav Med. 2008;31:341-9.

2. Husarewycz MN, El-Gabalawy R, Logsetty S, Sareen J. The association between number and type of traumatic life experiences and physical conditions in a nationally representative sample. Gen Hosp Psychiatry. 2014:36:26-32.

3. Sareen J, Cox BJ, Stein MB, Afifi TO, Fleet C, Asmundson GJG. Physical and mental comorbidity, disability, and suicidal behavior associated with posttraumatic stress disorder in a large community sample. Psychosom Med. 2007:69:242-8.

4. Pietrzak RH, Goldstein RB, Southwick SM, Grant BF. Physical health conditions associated with posttraumatic stress disorder in us older adults: results from wave 2 of the national epidemiologic survey on alcohol and related conditions. J Am Geriatr Soc. 2012;60:296-303.

5. El-Gabalawy R, Blaney C, Tsaie J, Sumnerg JA, Pietrzake RH. Physical health conditions associated with full and subthreshold PTSD in US military veterans: results from the National Health and Resilience in Veterans Study. J Affect Disord. 2018;227:849-53.

6. Britvic D, Anticevic V, Kaliterna M, Lusic L, Beg A, Brajevic-Gizdic I, Kudric M, Stupalo Z, Krolo V, Pivac N. Comorbidities with Posttraumatic Stress Disorder (PTSD) among combat veterans: 15 years postwar analysis. Int J Clin Health Psychol. 2015;15:81-92. 
7. Pacella ML, Hruska B, Delahanty DL. The physical health consequences of PTSD and PTSD symptoms: a meta-analytic review. J Anxiety Disord. 2013:27:33-46.

8. Husky MM, Mazure CM, Kovess-Masfety V. Gender differences in psychiatric and medical comorbidity with post-traumatic stress disorder. Compr Psychiatry. 2018;84:75-81

9. Cofini V, Carbonelli A, Cecilia MR, Binkin N, di Orio F. Post traumatic stress disorder and coping in a sample of adult survivors of the Italian earthquake. Psychiatry Res. 2015;229:353-8.

10. Carmassi C, Bertelloni CA, Gesi C, Conversano C, Stratta P, Massimetti G, Rossi A, Dell'Osso L. New DSM-5 PTSD guilt and shame symptoms among Italian earthquake survivors: impact on maladaptive behaviors. Psychiatry Res. 2017:251:142-7.

11. Mazza M, Giusti L, Albanese A, Mariano M, Pino MC, Roncone R. Social cognition disorders in military police officers affected by posttraumatic stress disorder after the attack of An-Nasiriyah in Iraq 2006. Psychiatry Res. 2012;198:248-52.

12. Ferretti F, Pozza A, Bossini L, Del Matto L, Desantis S, Olivola M, Gualtieri G, Coluccia A, Fagiolini A. A comparison of physical comorbidities in patients with posttraumatic stress disorder developed after a terrorist attack or other traumatic event. J Neurosci Res. 2019;97:543-53.

13. Pozza A, Bossini L, Ferretti F, Olivola M, Del Matto L, Desantis S, Fagiolini F, Coluccia A. The effects of terrorist attacks on symptom clusters of PTSD: a comparison with victims of other traumatic events. Psychiatr Qual. 2019;90:587-99.

14. American Psychiatric Association. Diagnostic and statistical manual of mental disorders, DSM-IV. 4th ed. Washington: Am Psychiatric Assoc; 1994

15. Carmassi C, Akiskal HS, Bessonov D, Massimetti G, Calderani E, Stratta P, Rossi A, Dell'Osso L. Gender differences in DSM-5 versus DSM-IV-TR PTSD prevalence and criteria comparison among 512 survivors to the L'Aquila earthquake. J Affect Disord. 2014;160:55-61.

16. Blake DD, Weathers FW, Nagy LN, Kaloupek DG, Klauminzer G, Charney DS, Keane TM. A clinician rating scale for assessing current and lifetime PTSD: the CAPS-I. Behav Ther. 1990;18:187-8.

17. Lecrubier $Y$, Sheehan DV, Weiller E, Amorim P, Bonora I, Sheehan KH, Janavs J, Dunbar GC. The Mini International Neuropsychiatric Interview (MINI). A short diagnostic structured interview: reliability and validity according to the CIDI. Eur Psychiatry. 1997;12:224-31.

18. Davidson JR, Rothbaum BO, van der Kolk BA, Sikes CR, Farfel GM. Multicenter, double-blind comparison of sertraline and placebo in the treatment of posttraumatic stress disorder. Arch Gen Psychiatry. 2001;58:485-92

19. Yates D, Moore D, McCabe G. The practice of statistics. 1st ed. New York: W.H. Freeman; 1999

20. Kinzie JD, Riley C, McFarland B, Hayes M, Boehnlein J, Leung P, Adams $\mathrm{G}$. High prevalence rates of diabetes and hypertension among refugee psychiatric patients. J Nerv Ment Dis. 2009;196:108-12.

21. Ching-En L, Chi-Hsiang C, Li-Fen C, Ching-Hui Y, Wu-Chien C, Po-Han C. Risk of incident hypertension, diabetes, and dyslipidemia after first posttraumatic stress disorder diagnosis: a nationwide cohort study in Taiwan. Gen Hosp Psychiatry. 2019;58:59-66.
22. Rosenbaum S, Stubbs B, Ward PB, Steel Z, Lederman O, Vancampfort D. The prevalence and risk of metabolic syndrome and its components among people with posttraumatic stress disorder: a systematic review and meta-analysis. Metabolism. 2015;64:926-33.

23. Babić R, Maslov B, Babić D, Vasilj I. The prevalence of metabolic syndrome in patients with posttraumatic stress disorder. Med Acad Most. 2013;1(1):45-50.

24. Rasmusson AM, Schnurr PP, Zukowska Z, Scioli E, Forman DE. Adaptation to extreme stress: post-traumatic stress disorder, neuropeptide $Y$ and metabolic syndrome. Exp Biol Med. 2010;235:1150-62.

25. Ralevski E, Southwick S, Jackson E, Jane JS, Russo M, Petrakis I. Traumaand stress-induced response in veterans with alcohol dependence and comorbid post-traumatic stress disorder. Alcohol Clin Exp Res. 2016:40:1752-60

26. McLeay SC, Harvey WM, Romaniuk MN, Crawford DH, Colquhoun DM, Young RM, Dwyer M, Gibson JM, O'Sullivan RA, Cooksley G, Strakosch CR, Lawford BR. Physical comorbidities of post-traumatic stress disorder in Australian Vietnam War veterans. Med J Aust. 2017;2017(206):251-7.

27. Park J, Marvar PJ, Liao P, Kankam ML, Norrholm SD, Downey RM, McCullough SA, Le NA, Rothbaum BO. Baroreflex dysfunction and augmented sympathetic nerve responses during mental stress in veterans with post-traumatic stress disorder. J Physiol. 2017;595:4893-908.

28. Miccoli R, Bianchi C, Odoguardi L, Penno G, Caricato F, Giovannitti MG, Pucci L, Del Prato S. Prevalence of the metabolic syndrome among Italian adults according to ATP III definition. Nutr Metabol Cardiovas Dis. 2005;15:250-4.

29. AIRTUM Working Group. Italian cancer figures, report 2014: prevalence and cure of cancer in Italy. Epidemiol Prev. 2014;38(6 Suppl 1):1-122.

30. Pace TW, Heim CM. A short review on the psychoneuroimmunology of posttraumatic stress disorder: from risk factors to medical comorbidities. Brain Behav Immun. 2011:25:6-13.

31. Giampaoli S, Palmieri L, Donfrancesco C, LoNoce C, Pilotto L, Vanuzzo D. Cardiovascular health in Italy. Ten-year surveillance of cardiovascular diseases and risk factors: osservatorio epidemiologico cardiovascolare/health examination Survey 1998-2012. Eur J Prev Cardiol. 2015;22(2):9-37.

32. Vancampfort D, Stubbs B, Mitchell AJ, De Hert M, Wampers M, Ward PB, Rosenbaum S, Correll CU. Risk of metabolic syndrome and its components in people with schizophrenia and related psychotic disorders, bipolar disorder and major depressive disorder: a systematic review and meta-analysis. World Psychiatry. 2015;14:339-47.

33. Pozza A, Lochner C, Ferretti F, Cuomo A, Coluccia A. Does higher severity really correlate with a worse quality of life in obsessive-compulsive disorder? A meta-regression. Neuropsychiatr Dis Treat. 2018;14:1013-23.

\section{Publisher's Note}

Springer Nature remains neutral with regard to jurisdictional claims in published maps and institutional affiliations.

Ready to submit your research? Choose BMC and benefit from

- fast, convenient online submission

- thorough peer review by experienced researchers in your field

- rapid publication on acceptance

- support for research data, including large and complex data types

- gold Open Access which fosters wider collaboration and increased citations

- maximum visibility for your research: over $100 \mathrm{M}$ website views per year

At $\mathrm{BMC}$, research is always in progress.

Learn more biomedcentral.com/submissions 